\title{
Fatores que moldam o comportamento dos burocratas de nível de rua no processo de implementação de políticas públicas
}

\author{
VICENTE DA ROCHA SOARES FERREIRA \\ Universidade Federal de GoIÁs / FACULdAde de AdMINISTRAÇÃO, CIÊNCIAS CONTÁBEIS E CIÊNCIAS ECONÔMICAS, \\ Programa de Pós-Graduação em Administração (PPGADM), GoIÂNIA - GO, BrasiL
}

JANANN JOSLIN MEDEIROS

Universidade de BrasílIa / FACULdAdE de ECONomia, AdMINISTRAÇÃo E CONTABILIDADE, Programa de Pós-Graduação em Administração (PPGADM), Brasília - DF, Brasil

\begin{abstract}
Resumo
A implementação é a transformação das intenções da política pública em resultados concretos entregues ao cidadão. O estudo desse processo pode ter orientação top-down, bottom-up ou, ainda, uma combinação dessas perspectivas. Na perspectiva bottom-up, o implementador de linha de frente (mais comumente denominado na literatura sobre o assunto como o "burocrata do nível de rua") é considerado um dos elementos centrais do processo de implementação, por causa de sua responsabilidade direta pela execução da política. Assim, este artigo apresenta uma análise da literatura que trata da atuação desse servidor público no processo de implementação, com o propósito de sistematizar o conhecimento sobre os fatores que o influenciam a realização de seu trabalho e apontar direções para futuras pesquisas. A análise, baseada no levantamento e na sistematização da produção bibliográfica voltada às questões que influenciaram a ação desse servidor público, apontou que o comportamento do burocrata de nível de rua é pautado por fatores pessoais, profissionais, gerenciais e políticos. A discussão desses fatores é organizada em seis subseções: discricionariedade; interações com o público da política; relações com o sistema de gestão; accountability; autointeresse; e normas, regras, crenças e valores. Nesse sentido, foi constatado que a pesquisa científica a respeito do burocrata de nível de rua é fragmentada, ora privilegiando uma, ora outra base teórica e foco de análise, de acordo com o interesse do pesquisador. Procurou-se, portanto, evidenciar como todos esses elementos se relacionam e como podem afetar o comportamento dos implementadores da linha de frente e o processo de implementação. Baseado na análise realizada, são sugeridas direções para futuras pesquisas. Palavras-chave: Implementação de política. Burocrata de nível de rua. Implementador de linha de frente.
\end{abstract}

\section{Factors that shape the behavior of street-level bureaucrats in the public policy implementation process}

\section{Abstract}

Implementation is the transformation of public policy objectives into concrete results delivered to citizens. The study of this process may be approached from the bottom-up or the top-down, or by some combination of these perspectives. From the bottom-up perspective, the frontline implementer (commonly called "street-level bureaucrat" in the literature on the subject), is regarded as a key element in the implementation process, due to his direct responsibility for policy execution. Thus, this article presents an analysis that addresses the work of this public servant during the implementation process, in order to systematize knowledge on the factors that influence how this work is carried out and indicate directions for further research. This analysis, based on survey and systematization of the literature on the subject, revealed that the behavior of a street-level bureaucrat is molded by personal, professional, managerial, and policy-related factors. The discussion of these factors is organized into six subsections: discretionary action; interaction with policy users; relations with the management system; accountability; self-interest; and standards, rules, beliefs, and values. In this sense, it was found that scientific research about the street-level bureaucrat is characterized by considerable fragmentation, with theoretical approach and focus of analysis varying in accordance with the interest of the respective researcher. Therefore, the article attempts to show how all of the different elements addressed in the literature are related and how they may affect the frontline implementer's behavior and the implementation process. Based on the analysis conducted, directions for further research are indicated.

Keywords: Policy implementation. Street-level bureaucrat. Frontline implementer.

\section{Los factores que determinan el comportamiento de los burócratas de nivel callejero en el proceso de implemen- tación de políticas públicas}

\section{Resumen}

La implementación es la transformación de las intenciones de la política pública en resultados concretos al ciudadano. El estudio de ese proceso puede orientarse por top-down ('de arriba abajo'), bottom-up ('de abajo arriba') o aún, a partir de una combinación de esas perspectivas. En la perspectiva bottom-up ('de abajo arriba'), el implementador que se encuentra en la línea de frente (más comúnmente nombrado, en la literatura sobre el asunto, como el "burócrata de nivel callejero") es considerado uno de los elementos centrales del proceso de implementación, debido a su responsabilidad directa por la ejecución de la política. Así, este artículo presenta un análisis de la literatura que trata de la actuación de ese servidor público en el proceso de implementación, con el propósito de sistematizar el conocimiento sobre los factores que influyen en la realización de su trabajo y determinar direcciones para futuras pesquisas. El análisis, basado en el levantamiento y en la sistematización de la producción bibliográfica relativa a las cuestiones que influyeron en la acción de ese servidor público, apuntó que el comportamiento del burócrata callejero está pautado por factores personales, profesionales, gerenciales y políticos. La discusión de esos factores está organizada en seis subsecciones: discrecionalidad; interacciones con el público de la política; relaciones con el sistema de gestión; accountability; autointerés; y normas, reglas, creencias y valores. En ese sentido, fue constatado que la pesquisa científica respecto al burócrata callejero es fragmentada, algunas veces privilegiando una, otras privilegiando otra base teórica y foco de análisis, de acuerdo con el interés del investigador. Por lo tanto, se procura evidenciar cómo todos esos elementos se relacionan y cómo pueden afectar el comportamiento de los implementadores de la línea de frente y el proceso de implementación. Basado en el análisis realizado, son sugeridas direcciones para futuras investigaciones.

Palabras clave: Implementación de la política. Burócrata de nivel callejero. Implementador de línea de frente. 


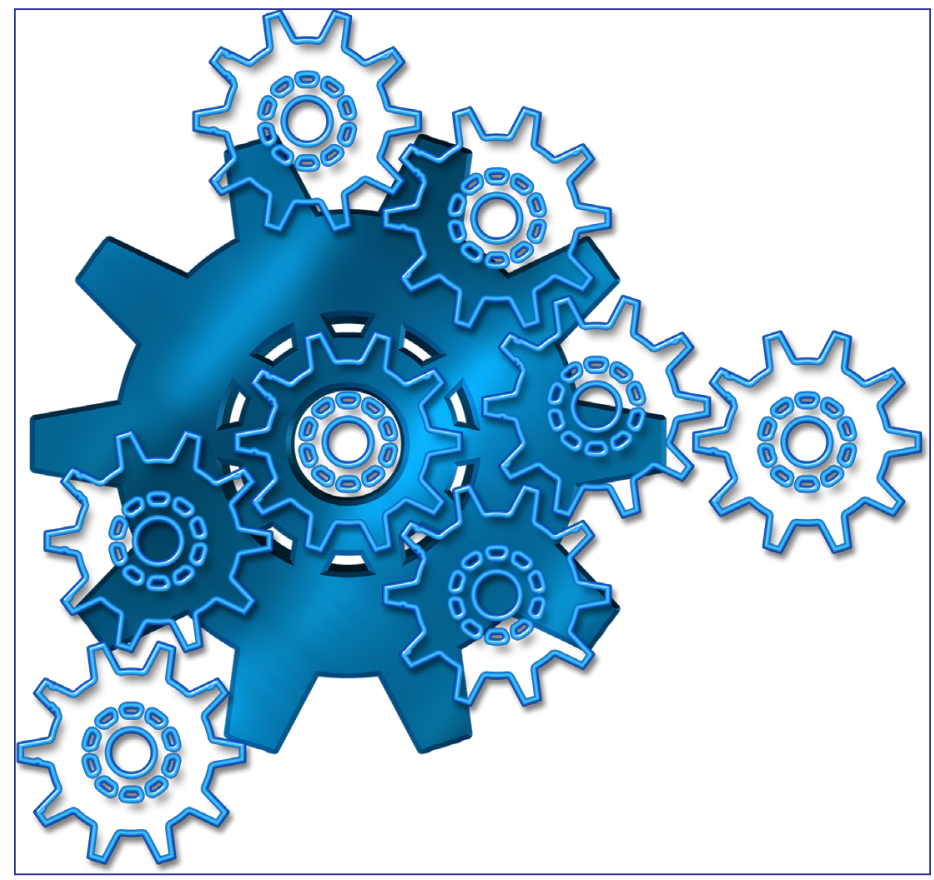

\section{INTRODUÇÃO}

A implementação é a operacionalização de uma decisão política, comumente estabelecida em uma lei, um programa ou mesmo em uma decisão judicial, constituindo-se em uma série de decisões e ações direcionadas a colocar uma decisão de governo em prática (LESTER e GOGGIN, 1998; SABATIER e MAZMANIAN, 1980; PALUMBO, MAYNARD-MOODY e WRIGHT, 1984). É pelo processo de implementação de políticas públicas que o Estado alcança os cidadãos que demandam seus serviços; ou seja, esse processo transforma o que é planejado numa política pública em serviços, de fato, entregues aos usuários ou cidadãos (FERMAN, 1990; JOHN, 2012; O'TOOLE, 2000; VAN METER e VAN HORN, 1975). Como tal, a formulação da política e sua implementação formam um processo que pode ser contínuo (LIPSKY, 2010), mas que também pode ser entrelaçado, o que leva Hill e Hupe (2002) a afirmarem que é inconcebível pensar a implementação como um processo que ocorre unicamente depois e independentemente da formulação da política.

Nos primórdios dos estudos acadêmicos sobre implementação, Majone e Wildavsky (1984) perguntaram: seria a política um plano articulado, necessitando apenas de aplicação, ou a política é uma premissa necessária para algo que vem depois? Atualmente, parece mais adequado pensar a política como uma premissa para a implementação, pois segundo Lipsky (2010, p.213), hoje não há discordância de que uma política somente existe quando a lei ou os regulamentos que a criaram são implementados. Desse ponto de vista, portanto, a implementação ganha importância central no processo da política (policy process), o que não tem sido a realidade da pesquisa nesse campo, no qual os processos de formulação e avaliação têm sido proeminentes (HILL e HUPE, 2002; LOTTA e PAVEZ, 2010), centrando a atenção nos usuários dos serviços, ou nos resultados e esquecendo-se do papel dos implementadores envolvidos no processo de implementação (TENDLER, 1998).

Apesar da maior atenção dispensada aos processos de formulação e avaliação, ao longo dos últimos 40 anos foi produzida uma considerável literatura dedicada a compreender o processo de implementação. No início desses estudos, a maior preocupação era explicar o déficit entre o que é formulado e o que é implementado, a começar pelo estudo clássico de Pressman e Wildavsky (1984), que procurou entender por que os programas governamentais falham. Com as mesmas preocupações,

\footnotetext{
* Fonte da imagem: Pixabay. Disponível em <https://pixabay.com/pt/engrenagens-equipe-juntos-fun\%C3\%A7\%C3\%A3o-1059756/>. Acesso em 27 jul. 2016.
} 
Van Meter e Van Horn (1975) levantaram duas questões: por que se sabe tão pouco sobre os problemas da implementação de políticas? Se é um problema de grande importância para a sociedade porque não são feitos maiores esforços para identificar suas falhas básicas? A resposta dos autores indica que talvez isso decorra do pressuposto ingênuo de que uma vez a política estabelecida, esta será implementada e os resultados desejados alcançados.

Pressman e Wildavsky (1984) - os principais representantes da primeira geração de estudos de implementação - apontaram o número de atores, os pontos de decisão e a validade da teoria causal como principais variáveis teóricas para explicar o sucesso (ou fracasso) da implementação da política conforme formulada. Os autores apontaram, ainda, a complexidade da ação conjunta como o principal problema de implementação.

Quanto aos estudos de segunda geração de implementação (tendo o trabalho de Lipsky [1980] sobre a burocracia de nível de rua como um de seus principais marcos), estes se preocuparam em explicar as falhas ou o sucesso da implementação, desenvolvendo modelos teóricos de análise que orientassem a pesquisa empírica a partir do ponto em que o Estado encontra os cidadãos e as empresas, com ênfase na influência dos trabalhadores de linha de frente na execução das políticas (LESTER, BOWMAN, GOGGIN et al., 1987; WINTER, 2010).

Assim, em busca da identificação dos fatores de implementação que afetam o alcance dos objetivos estabelecidos pela política (SABATIER e MAZMANIAN, 1980), bem como de respostas para uma melhor compreensão do sucesso ou do fracasso da implementação (MEYERS e VORSANGER, 2010), o campo de pesquisa adota inicialmente duas perspectivas distintas:(1) a topdown, ou seja, de cima para baixo, em que a implementação é vista como um processo racional e planejado, enfatizando o comando, o controle e a uniformidade. Estudos que adotam essa perspectiva colocam os formuladores como atores centrais e concentrando sua atenção em fatores que podem ser manipulados no nível central do governo (LINDER e PETERS, 1987; MATLAND, 1995; TUMMERS, STEIJN e BEKKERS, 2012; WINTER, 2010). Dessa forma, compreendem a implementação como um processo de fidelidade aos objetivos dos formuladores das políticas, estando, portanto, submetida ao controle hierárquico ou ao controle da lei; (2) a perspectiva bottom-up, ou seja, de baixo para cima. Nessa perspectiva, argumenta-se que a política de fato é realizada em nível local, a implementação é compreendida como um processo dinâmico e interativo entre servidores públicos e os usuários de serviços públicos, e o foco está nos grupos-alvo e nos prestadores de serviços (MATLAND, 1995; TUMMERS, STEIJN e BEKKERS, 2012). Assim, compreende-se a implementação como um processo de adaptação das políticas durante o sua execução, podendo ser um processo de negociação explícita ou implícita entre os membros do órgão público responsável pela implementação, os implementadores da linha de frente e seus usuários (LINDER e PETERS, 1987; LOTTA e PAVEZ, 2010; MEYERS e VORSANGER, 2010).

Matland (1995) exemplifica uma terceira geração de pesquisas, em que propõe uma síntese das duas perspectivas apontadas. Nessa proposta-síntese, o autor apresenta as condições sob as quais é mais apropriada uma abordagem top-down ou bottom-up. Isto é, reafirma não existir, a priori, uma abordagem melhor do que a outra.

Independentemente da perspectiva adotada, a maior preocupação nos estudos de implementação tem sido compreender o porquê das diferenças entre a política formulada e a política realizada, e, já que parece consensual que existe mesmo essa diferença (MAY e WINTER, 2007), encontrar seus fatores influenciadores, os quais incluem os implementadores. Cabe observar que mesmo autores pioneiros da primeira geração de estudos, como Van Meter e Van Horn (1975), já compreendiam a implementação como o processo que engloba ações desenvolvidas por indivíduos e grupos, dirigido ao alcance dos objetivos estabelecidos em decisões políticas a priori (perspectiva top-down), mas já identificando os implementadores como elementos essenciais do processo de implementação. Essa também é a percepção de Palumbo, Maynard-Moody e Wright (1984), para os quais a implementação de sucesso precisa atingir todas as camadas da hierarquia organizacional e envolver os implementadores de nível de rua nesse processo.

Para Lipsky (2010), os profissionais que interagem diretamente com os cidadãos - tais como professores, profissionais da saúde, juízes e defensores públicos - são os burocratas de nível de rua. Para esse autor, os implementadores podem, ao implementar a política, definir sua direção, ao escolher os benefícios e as sanções que vão impactar a vida das pessoas que têm alguma relação com a política. Hupe e Hill (2007) acreditam que como as decisões desses profissionais na linha de frente do serviço público têm consequências públicas, justifica-se a pesquisa sobre sua real participação no processo de implementação. No entanto, Meyers e Vorsanger (2010) alegam que, muitas vezes, o trabalho da linha de frente é ignorado pela enorme dificuldade de se pesquisar esse processo, e afirmam que dar maior importância às "atividades e influências dos burocratas de nível de rua enriquecerá a compreensão sobre êxitos e fracassos na implementação" (Ibidem, p. 268). 
Neste estudo também se compreende a implementação como um processo que começa pela base da política; ou seja, pelo implementador localizado na linha de frente (ou burocrata de nível de rua, como é comumente tratado na literatura), sendo sobre esse indivíduo que recai toda a análise realizada neste estudo. Como já ponderado, esse indivíduo, na sua atuação, além de implementar, também pode moldar os rumos e resultados da política. Dessa forma, diante do papel estratégico do burocrata de rua na implementação de políticas públicas, do conhecimento pouco sistematizado sobre seu comportamento e de como isso impacta o desempenho das políticas públicas (PIRES, 2009b), este artigo propõe uma análise da atuação dos implementadores de linha de frente, visando identificar e descrever os fatores que influenciam o comportamento dos implementadores de linha de frente e as consequências no seu desempenho e no da própria politica.

Com esse objetivo, realizou-se uma sistematização da literatura sobre os fatores influenciadores das decisões e ações do burocrata de nível de rua. O primeiro passo foi rever os principais estudos do campo de implementação. Considerando que o foco da análise pretendida foi no implementador de nível de rua, tomou-se como ponto de partida o trabalho de Lipsky, sendo levantados nas principais bases eletrônicas de dados os mais citados trabalhos voltados ao processo de implementação à luz da burocracia de nível de rua (termo cunhado por Lipsky, largamente utilizado por pesquisadores interessados na atuação dos implementadores da linha de frente). Foi, então, realizada a análise de conteúdo para a identificação dos fatores que influenciariam o comportamento do burocrata de nível de rua no processo de implementação. Na base dessa análise, foram identificados seis fatores que moldariam a atuação desse servidor público, os quais são discutidos adiante: discricionariedade; interações com o público da política; relações com o sistema de gestão; accountability, autointeresse; e normas, regras, crenças e valores.

Dentre os trabalhos internacionais analisados destacam-se os de Brodkin (2012); May e Winter (2007); Maynard-Moody e Musheno (2000; 2003; 2012); Meyers e Vorsanger (2010); Tummers (2013); Tummers, Steijn e Bekkers (2012), e Winter (2003). Do Brasil, foram analisados os trabalhos de Antezana (2013); Lotta e Pavez (2010); Oliveira (2012) e Pires (2009a; 2009b), não sendo identificados outros pesquisadores sobre o tema no Brasil.

A seguir, são discutidos os fatores identificados na pesquisa:

\section{FATORES INFLUENCIADORES DO COMPORTAMENTO DO IMPLEMENTADOR DO NÍVEL DE RUA}

Conforme mencionado, na depuração dos fatores que influenciam o comportamento do implementador do nível de rua no processo de implementação, foram observados fatores pessoais (crenças, valores, altruísmo, vocação, autointeresse e poder discricionário), fatores institucionais e gerenciais da política (discricionariedade, sistemas de controle, accountability, leis, normas e regras, recursos, sistemas de incentivo, padrões de desempenho e estrutura de poder) e fatores relacionais (com o público da política, com os gerentes e com os políticos). A organização nessas categorias, no entanto, não pode ser seguida linearmente na discussão apresentada aqui, tendo em vista que elementos como a discricionariedade tanto podem ser apenas uma regra abstrata quanto uma ação exercida pelo burocrata; assim como as crenças e os valores podem derivar de elementos institucionalizados tanto quanto de fatores ambientais em toda a cadeia de implementação, e assim por diante.

Assim, além da introdução, este artigo está organizado em duas seções. Nesta primeira, são analisados os fatores influenciadores do comportamento do implementador no nível de rua. Nela, são apresentados e discutidos em seis subseções os seguintes temas: a discricionariedade e o controle do implementador de linha da frente; as interações desse implementador com os usuários da política; o implementador do nível de rua e o sistema de gestão da política; o implementador e os processos de accountability; os implementadores e seu comportamento autointeressado; e o implementador e os dispositivos institucionais (normas, regras, crenças e valores). Na segunda seção, temos a proposta de relacionamento dos fatores influenciadores da burocracia de nível de rua, seguida das considerações finais.

\section{A DISCRICIONARIEDADE E O CONTROLE DA BUROCRACIA DO NÍVEL DE RUA}

Nesta seção procura-se caracterizar o implementador de nível de rua, assim como compreender suas decisões e ações no espaço da política que a teoria define como discricionariedade. Dessa forma, demonstra-se como a discricionariedade pode influenciar o comportamento de entrega de serviços desse implementador no processo de implementação. 

políticas públicas

No conjunto das teorias que procuram explicar o fenômeno da implementação, a abordagem dos burocratas de nível de rua tem se tornado um tema de amplo interesse acadêmico (BRODKIN, 2012). Compreende-se, neste artigo, que a burocracia do nível de rua é constituída de indivíduos caracterizados por capacidades, percepções e preferências específicas, tomando-se como base uma definição de ator individual concebida por Scharpf (1997). Essa definição de ator individual, à primeira vista, parece se chocar com o conceito de burocracia, pelo fato desse conceito carregar uma conotação negativa, principalmente, devido às suas disfunções, desde os estudos iniciais sobre esse tipo de organização. Maynard-Moody Musheno (2003) afirmam que os implementadores de nível de rua rejeitam o qualificativo de burocrata. Pode também parecer um contrassenso incluir um ator com as características descritas em um tipo de organização que teoricamente possa restringir seu espaço de ação.

Aliás, essa contradição já fora apontada por Lipsky (2010) ao afirmar que, se por um lado, os serviços são produzidos por pessoas e fornecidos a pessoas por meio de interações humanas no nível de rua, por outro, esse processo ocorre por meio de uma burocracia, conceituada pelo autor como um conjunto de regras e estruturas de autoridade. Portanto, as relações do nível de rua estão distantes do espaço onde presumivelmente a autoridade se encontra. Por isso, é preciso esclarecer que os estudos sobre esse tipo de implementador de política apresentam-no implicitamente com o conceito adotado neste artigo, ou seja, indivíduos que agem guiados por suas capacidades, percepções e preferências específicas. Neste estudo são utilizados como sinônimos intercambiáveis os termos burocrata de rua, profissional de linha de frente, implementador do nível de rua e implementador de linha de frente, em referência aos indivíduos do serviço público que atuam diretamente na interface com o cidadão na entrega de serviços públicos.

Na análise do papel dos atores implementadores do nível de rua, Lipsky (2010) afirma que esses funcionários públicos são os responsáveis por garantir a cidadania. Para demonstrar a importância desses profissionais, o autor cita a quantidade de funcionários públicos existentes em muitos setores dos Estados Unidos, assim como a grande quantidade de recursos alocados para remunerá-los, o que confere grande peso a essa força de trabalho do Estado, além da grande força que têm esses funcionários para controlar seus ambientes de trabalho através de suas associações e sindicatos. Esse quadro de justificativas também poderia ser aplicado a países como o Brasil, sem qualquer prejuízo ao processo de análise.

Sem dúvida, o trabalho de Lipsky é a fonte que mais tem influenciado os estudos sobre os operadores de linha de frente das políticas públicas, considerando-se neste estudo que operador de política é um sinônimo de implementador de linha de frente. A partir desse trabalho, muitas outras abordagens teóricas surgiram no esforço para compreender como age o implementador de linha de frente no processo de implementação, ou, nas palavras de Maynard-Moody e Musheno (2003), por que os trabalhadores de nível de rua fazem o que fazem. Dado o papel estratégico dispensado ao burocrata de rua pela teoria, a pesquisa, independentemente da abordagem teórica adotada, tem procurado descobrir o que mobiliza esses atores em direção à implementação ou por que o burocrata age desta ou daquela maneira.

E por que o papel desses profissionais é estratégico no processo de implementação? Para Brodkin (2012), essa importância é devida ao fato de que esses trabalhadores são o núcleo operacional do Estado. Mais do que apenas funcionários públicos, parecem ser agentes principais no desenvolvimento de seus papéis profissionais na implementação de políticas (MAY e WINTER, 2007). Já Lipsky (2010) acredita que é porque eles têm grande poder sobre a vida das pessoas: por um lado podem, ao aumentarem ou diminuírem a disponibilidade de benefícios de uma política para a população mais pobre, mudar a vida dessas pessoas por meio de suas decisões e ações. Por outro lado, com essas ações, estariam implicitamente regulando o grau de redistribuição da renda que seria paga a outros setores sociais mais influentes da sociedade, por exemplo. Mas Lipsky (2010, p. 14) ressalva que as principais dimensões da política pública, tais como níveis de benefícios, categorias de elegibilidade, natureza das regras, regulamentos e serviços são moldados pelas elites da política pública, entre eles os políticos e os funcionários administrativos.

No entanto, parece que o aspecto mais relevante para se compreender o papel do burocrata de nível de rua no processo de implementação seja seu poder discricionário, que pode ser originário de duas fontes: uma da profissão, já que esses trabalhadores são profissionais - ou seja, pertencem a uma categoria profissional e exercem a discrição natural daquela carreira (HUPE e HILL, 2007; TUMMERS, 2013) - e outra advinda de sua condição de funcionário público, o que significa que mesmo funcionários que não tenham o status de profissional exercem o poder discricionário, ao determinarem os usuários que têm acesso a benefícios, ainda que essa discricionariedade esteja circunscrita por regras e submetida à supervisão (LIPSKY, 2010). 
A discricionariedade é a amplitude de espaço de decisão que esses trabalhadores têm no processo de implementação (HILL e HUPE, 2002; LIPSKY, 2010). Essa discricionariedade também é objeto de estudo de outras áreas do conhecimento, e sua definição pelos profissionais do direito, por exemplo, refere-se à margem de liberdade que tem o servidor público para tomar uma decisão de escolha dentre, pelo menos, duas situações cabíveis perante cada caso concreto. Assim, poderá adotar a solução mais adequada à satisfação da finalidade legal quando da interpretação da lei não puder ser extraída uma solução objetiva (MELLO, 2010). Isso significa que a interpretação da lei é uma prerrogativa dada como certa ao operador da política, o que sustenta a afirmação de Lipsky (2010) de que esse grupo de atores da política detém grande poder sobre o que deve ou não ser realizado.

Para Lipsky (2010), a discricionariedade é um conceito relativo. O autor afirma que, teoricamente, os problemas do serviço público desapareceriam se a discricionariedade fosse eliminada, mas as características intrínsecas do trabalho desses profissionais não permite que a discricionariedade seja reduzida drasticamente. Isso decorre da complexidade das tarefas que impede que a elaboração de regras, guias ou instruções circunscrevam todas as alternativas. $O$ autor exemplifica com o caso de policiais que se recusariam a intervir em situações potencialmente danosas se instruções fossem estabelecidas e promulgadas. O mesmo valeria para professores, para os quais situações específicas requerem respostas específicas, o que impede o preestabelecimento de regras para a sua atuação. Lipsky destaca, ainda, que os cidadãos usuários de serviços públicos querem decisões únicas para situações únicas; ou seja, aprovam a flexibilidade dos profissionais na interpretação da lei e suas normas.

No entanto, essa liberdade na interpretação da política carrega no seu bojo a necessidade de controle. A inevitabilidade do julgamento humano pelo burocrata no nível de rua e a posição desses burocratas como formuladores de política, de fato, tornam crítica a supervisão desses profissionais pelos seus superiores, dificultando o controle e o gerenciamento dos trabalhadores do nível de rua (HUPE e HILL, 2007), principalmente, na forma como o trabalho é realizado. Um exemplo ocorre quando os trabalhadores refugam desenvolver suas atividades de determinada forma ou quando executam apenas o mínimo dessas atividades ou, ainda, quando se frustram pela forma como são gerenciados (PIRES, 2009a). O desencontro entre burocrata e gestor acontece porque, como se sabe, os trabalhadores buscam a maximização de sua autonomia na função de "processamento de usuários" enquanto os gerentes procuram minimizar essa autonomia por meio do controle, com vistas ao resultado agregado (LIPSKY, 2010). Contudo, Lipsky é otimista quanto à ação dos burocratas de rua com seu poder discricionário, destacando que, perante a obrigação geral e difusa do interesse público, é possível esperar que o funcionário público adote a melhor orientação para atender ao cidadão.

Hupe e Hill (2007) destacam que regras e discricionariedade estão relacionadas, e observam que, como as regras estabelecem deveres e obrigações para os funcionários públicos, a discricionariedade Ihes garante liberdade de ação. Esses autores afirmam ainda que quase todo assunto normatizado é passível de interpretação, sendo particularmente o caso de regras complexas que objetivam garantir benefícios ou serviços. Este seria o caso das políticas públicas, dentro das quais os atores podem se deparar com situações em que as regras são ambíguas ou mesmo contraditórias. Nessas situações a interpretação é necessária, pelo fato de que os atores precisam tomar decisões, precisam prestar o serviço, mesmo diante da ambiguidade (ANTEZANA, 2013). Assim, em ambientes onde as políticas públicas são formuladas de forma centralizada para serem implementadas de maneira homogênea (LIMA e MEDEIROS, 2012; LOTTA e PAVEZ, 2010) a preocupação talvez seja como aumentar a discrição ao contrário da preocupação de Davis (1969), observado por Hill e Hupe (2002), que era aumentar o controle da discrição.

Meyers e Vorsanger (2010) afirmam que grande parte do que é produzido no serviço público é intangível. Isso seria uma característica geral dos serviços que, além de dificultar a avaliação e o monitoramento, também prejudicaria, por consequência, a gestão. Destacam também que, em grande parte, a produção dos serviços é realizada na interface com os usuários, o que gera variabilidade e imprevisibilidade no trabalho desses burocratas, aumentando a necessidade de discricionariedade. Assim como Lipsky (2010), Meyers e Vorsanger (2010), destacam que esses burocratas não só executam as políticas, mas moldam seus resultados, por meio da interpretação de regras e da alocação de recursos escassos.

Essa também é a opinião de Oliveira (2012), para quem a quantidade e a qualidade dos serviços públicos dependem do poder discricionário do burocrata de nível de rua, o que enseja a necessidade de se conhecer seus determinantes e as consequências destes. $\mathrm{O}$ autor aponta ainda que esses profissionais, além de serem os responsáveis pela tradução dos programas em produtos e serviços, precisam ir além dos objetivos estabelecidos na fase de formulação porque os formuladores, muitas vezes, não sabem o que querem das políticas e o resultado são políticas com objetivos vagos, gerais ou inconsistentes. Diante disso, cabe 
aos executores de linha de frente a interpretação e a decisão sobre a maneira mais adequada para implementar a política; ou seja, não só executam as políticas, mas por meio de suas interpretações, decisões e ações também constroem as políticas.

Como é perceptível, a teoria aponta para a inevitabilidade e a desejabilidade da discricionariedade para adaptar as políticas às necessidades individuais (MEYERS e VORSANGER, 2010). Diante disso, surge outro desafio: como ficaria a questão do controle diante do exercício da discricionariedade? Para Meyers e Vorsanger (2010), é possível que o exercício do poder discricionário com accountability mínima conceda aos trabalhadores poder indevido na execução de suas obrigações e na alocação de recursos públicos. Por exemplo, ao atuarem segundo seus próprios preconceitos, podem escolher aqueles que receberão públicos de forma indevida. Pires (2009a) demonstrou o contrário. Encontrou evidências de que quando fiscais do trabalho receberam mais poder discricionário para agir, foram capazes de produzir melhores resultados do que aqueles que recebiam maior controle de suas ações. Meyers e Vorsanger (2010) afirmam, ainda, que muitos pesquisadores têm examinado fatores políticos, organizacionais e profissionais que controlariam a discricionariedade no nível de rua, mas os resultados são muitas vezes contraditórios, e, no conjunto, sugerem mais complexidade do que contradição.

A complexidade pode derivar do fato de que o objeto é observado a partir de diferentes perspectivas teóricas e campos distintos. No campo do direito administrativo, a preocupação é prescrever e normatizar a estrutura de responsabilidade e deveres dos burocratas. No campo da economia, a preocupação é com a construção de modelos econômicos racionais que procurem evitar o comportamento de shirking (WILSON, 2000) ou comportamento de fuga do burocrata em relação a suas responsabilidades. Já no campo das ciências políticas, surgem as propostas de modelos de controle político e social que objetivam a conformidade dos trabalhadores do nível de rua à política. Porém, faltam estudos na literatura que busquem identificar quais áreas ou tarefas demandam maior ou menor discricionariedade, tanto em função das características do trabalho quanto das características profissionais desses trabalhadores. Tal desafio pode se fazer necessário pelo fato de que trabalhadores de nível de rua podem invocar regras e leis, predominantemente, para se protegerem ou justificarem suas próprias decisões e ações (MAYNARD-MOODY e MUSHENO, 2012).

A inexistência de estudos sobre formas de gestão da discricionariedade ocorre, principalmente, em situações em que não se consegue observar, medir e controlar o comportamento de entrega do serviço. Isso é uma das preocupações da teoria agente-principal (WILSON, 2000; WINTER, 2003), seja porque tal comportamento só se manifesta na relação direta burocrata-cidadão, conforme apontado por vários autores - entre eles, Bartels (2013) e Lotta e Pavez (2010) -, seja porque depende de fatores intrínsecos ao prestador do serviço, como apontado por Antezana (2013), ou ainda por causa da assimetria de informações, como observado por Winter (2003).

É possível, também, que haja problemas de controle quando o operador da política não queira exercer o poder da discricionariedade em situações concretas por causa de fatores pessoais, profissionais, administrativos (controle interno e externo) e políticos, entre outros. Nesses casos, haveria o problema oposto, não de controle de excesso de discricionariedade, mas de omissão da interpretação do que abstratamente prescreve a legislação. Como na etapa da formulação da política é quase impossível enquadrar a realidade tal como ela ocorre, o legislador ou formulador abre espaço para a discricionariedade que o implementador deveria exercer, mas pelos motivos apontados, não a exerce. Essa omissão também pode influenciar o resultado das políticas. A norma aplicada sem nenhuma interpretação é uma decisão supostamente neutra, mas que não deixa de ser uma forma de decisão que afetará os resultados da política. A teoria, no entanto, não parece estar preocupada com esse tipo de raciocínio, pois inexistem estudos nesse sentido.

O raciocínio apresentado, entretanto, não invalida a preocupação da teoria com o exercício da discricionariedade, mas levanta outro pressuposto sobre a omissão de seu exercício. Assim, considera-se que a discricionariedade é característica intrínseca da burocracia de nível de rua e que existem evidências substanciais de que seu exercício pode contribuir para o processo da política, moldando o comportamento desses profissionais e produzindo melhores resultados (BURKE, 1990; LIPSKY, 2010; PIRES, 2009a), mas que também sua omissão pode ter implicações significativas para a implementação.

\section{O IMPLEMENTADOR E SUAS INTERAÇÕES COM OS USUÁRIOS DA POLÍTICA}

Esta subseção trata da relação do burocrata de nível de rua com o cidadão usuário ou cliente da política. Parece lógico que as relações que se estabelecem no nível de rua entre implementador e usuário são importantes por representarem o governo em 

políticas públicas

ação, momento em que este executa suas políticas. Além disso, é o espaço próprio da implementação, onde ocorrem a produção do serviço, os resultados e os impactos da política pública. É onde se observa se a política foi ou não foi implementada.

As interações entre o implementador de nível de rua e o cidadão podem influenciar o burocrata a agir de forma a melhor desempenhar os objetivos da política. Lipsky (2010) argumenta que os determinantes das práticas do nível de rua estão profundamente enraizados na estrutura do trabalho, e que as organizações públicas refletem as relações organizacionais prevalecentes na sociedade como um todo. Especificamente, o autor aponta as interações regulares que os servidores têm com os cidadãos e as condições de trabalho desses servidores (Ibid., p. 27-28) como fatores fundamentais na explicação de seu comportamento. $\mathrm{O}$ autor alerta, no entanto, que nenhum desses fatores isoladamente é suficiente para explicar como agem esses trabalhadores, mas podem moldar seu comportamento para melhor desempenharem seu papel estratégico na implementação da política pública.

Lipsky (2010) parece apontar para uma dependência mútua entre burocratas de rua e usuários da política. Por um lado, Lipsky ressalva que em algum sentido este servidor depende do usuário, principalmente, quando é avaliado por parâmetros que dependem da opinião desse usuário. $O$ autor destaca que, na verdade, o implementador da linha de frente depende do consentimento do usuário para suas decisões e ações, o que não deixa de ser um tipo de legitimidade para as ações do servidor e do próprio governo. Por outro, o burocrata de rua pode controlar o comportamento do usuário pelo fato deste ser quase sempre não voluntário, o que ocorre quando o usuário depende de serviços públicos monopolizados, por exemplo. Nessas situações, é o burocrata de rua que influencia o comportamento do usuário, o que pode redundar no consentimento deste para apoiar as decisões e ações daquele.

Tummers, Steijn e Bekkers (2012) também sustentam que a qualidade das interações entre profissionais e cidadãos pode influenciar a legitimidade do governo. E parece claro que a relação que esses profissionais estabelecem com os cidadãos, além de serem fundamentais ao exercício da ação de governo, tornam legítimas essas ações. Para isso, a qualidade da interação se torna crucial porque o serviço da política é produzido no momento dessa interação. Considerando a própria natureza da produção do serviço, que é consumido pelo usuário no ato de sua produção, se o cidadão não perceber a importância do serviço, isso terá implicações para o governo.

Essas interações também contribuem para influenciar o comportamento dos implementadores, pela realidade vivida, diante da qual precisam tomar uma decisão, o que ocorre em um encontro público, processo em que o profissional e o cidadão interagem na coprodução e entrega das políticas, no qual trabalhadores e cidadãos podem aperfeiçoar a qualidade da entrega do serviço público, a tomada de decisão e a solução de problemas (BARTELS, 2013). Bartels destaca, ainda, que a abordagem tradicional vê uma discrepância entre as decisões políticas e a prática dos profissionais, além de procurar por estruturas organizacionais, ferramentas gerenciais e regulações de politicas que possam promover o exercício efetivo e responsável da discricionariedade, uma visão que pode limitar a compreensão de como os profissionais e cidadãos podem interagir para aperfeiçoar a qualidade da entrega do serviço público (Ibid., p. 4).

Ainda quanto ao relacionamento entre implementador e cidadão, Tendler (1998) acredita que a confiança surgida dessa relação ajuda a personalizar um serviço que os manuais de política tentam estruturar, o que a autora considera ser um dos problemas de implementação. Dessa personalização decorre outro problema de implementação no setor público, que é a restrição do princípio legal da impessoalidade, pelo qual todos os cidadãos devem ser tratados de forma igualitária. De fato, o implementador da linha de frente enfrenta um dilema entre o atendimento diferenciado demandado pelo cidadão e a "predominância de um espírito de impessoalidade" arraigado nas estruturas burocráticas (WEBER, 1966, p. 27), o que pode resultar em tensões entre o implementador e o cidadão. Algumas vezes, o tão socialmente propalado "jeitinho brasileiro" pode pautar a decisão, o que não é novidade nas relações Estado-Sociedade na história do Brasil.

Em um dos poucos estudos brasileiros sobre a burocracia do nível de rua, Lotta e Pavez (2010) analisaram, numa perspectiva relacional entre burocratas e beneficiários das políticas, como os agentes de implementação de um programa público federal desenvolvem suas práticas em nível local, assim como os fatores que as influenciam, procurando, com isso, conhecerem as consequências dessas práticas no acesso da população aos serviços públicos dessa política. Conforme as autoras, as ações dos programas que estavam sendo implementados foram construídas nas relações entre burocratas de rua e comunidade, de tal forma que os resultados, em sua maioria, eram diferentes daqueles previstos na formulação, resultado que demonstra a importância dessa relação no plano da implementação. 
E quando não há interação com os usuários na entrega do serviço? Keiser (2010) analisou casos em que os burocratas de rua têm altos níveis de discrição, mas falta interação face a face com o usuário. A autora destaca que a teoria tem mostrado a importância das interações face a face entre usuários e implementadores de linha de frente como característica central da entrega de serviços públicos, mas que com o avanço da tecnologia da informação, essa característica vem sendo perdida. Seu estudo é um esforço para gerar e testar hipóteses que expliquem a variação no modo como os profissionais de linha de frente implementam política quando não existem interações face a face.

Entretanto, ao contrário do que afirma Keiser (2010), não parece que a interação face a face seja uma característica que mude substancialmente a relação dos implementadores de linha de frente com seus clientes, porque a relação continua existindo diante da necessidade de produção e da entrega do serviço da política aos cidadãos. Essa também parece ser a visão de Lipsky (2010), que afirma que os sistemas de informações não eliminam as preocupações com a responsividade, que é o tratamento das pessoas como indivíduos que podem possuir características e necessidades únicas.

Pode-se compreender, portanto, que as interações ou encontros públicos (como preferem alguns pesquisadores) entre implementadores e cidadãos na implementação da política representam grandes desafios, mas também oportunidades na execução da política. Como desafios, melhorar a gestão e a qualidade do serviço público aos cidadãos, mesmo sendo estes, quase sempre, usuários não voluntários (LIPSKY, 2010), e, como principal oportunidade, a possibilidade de envolvimento da comunidade na produção de serviços que sejam de seu interesse, evitando a implementação desconectada da realidade dos principais interessados.

\section{O IMPLEMENTADOR DO NÍVEL DE RUA E O SISTEMA DE GESTÃO DA POLÍTICA}

Enquanto na subseção anterior a discussão esteve centrada na relação implementador-cidadão, nesta a análise recairá sobre outros fatores que também podem explicar ou determinar a forma de agir desses profissionais, tais como os relacionamentos intrapolítica ou intraorganizacional. Lipsky (2010) afirma que em geral os burocratas de nível de rua têm prioridades diferentes dos gerentes de suas organizações. Os burocratas de rua buscam, pelo menos, minimizar os danos e os desconfortos do trabaIho além da satisfação pessoal. Para o autor, essas prioridades só interessam aos gerentes enquanto estiveram relacionadas à produtividade, à eficiência e levarem a resultados consistentes com os objetivos da organização para a qual estes trabalham.

May e Winter (2007) em um estudo que procurou compreender, entre outros, os fatores gerenciais e políticos que influenciam os implementadores de linha de frente na implementação de políticas, encontraram resultados que apontam influência dos níveis mais altos da política pública sobre o comportamento desses profissionais, embora essas influências não apresentassem fortes relações na explicação desses comportamentos. Além do mais, quando se analisa comportamentos burocráticos pouco visíveis - tais como estilo de aplicação de uma norma e a rigidez com que o burocrata reage às violações de regras -, a influência dos políticos tem pouca ou nenhuma influência sobre essas práticas (WINTER, 2010).

No entanto, May e Winter (2007) também apontam que entre os fatores encontrados na literatura que influenciam o comportamento dos trabalhadores de linha de frente estão os sinais dados pelos superiores políticos, os arranjos organizacionais, a ênfase administrativa nos objetivos da política, o aperfeiçoamento da capacidade das pessoas e a supervisão gerencial. Os autores observam, no entanto, que a influência dos fatores gerenciais apontados na literatura sobre o comportamento do implementador é fraca. Mesmo assim, May e Winter (2007) destacam três desses fatores, em particular, que apresentam algum tipo de influência: a supervisão, a comunicação dos objetivos e a delegação na tomada de decisão para os profissionais de linha de frente. No entanto, Meyers e Vorsanger (2010) acrescentam que as organizações funcionam como instrumentos de políticas por meio de muitos fatores, entre estes, padrões de desempenho, recompensas e penalidades, "que tanto refletem como fazem cumprir os objetivos dos funcionários responsáveis por políticas" (Ibid., p. 261). Isso implica a relação do burocrata de rua com o processo gerencial, mesmo que tal relação seja menos importante do que aquelas existentes entre outros elementos da política.

E por que seria baixa ou mesmo inexistente a influência dos escalões superiores da política sobre os implementadores de linha de frente, se aqueles são os responsáveis por medir desempenho e estabelecer recompensas e penalidades no nível organizacional da política? A explicação mais óbvia parece ser a de que o nível político (e, muitas vezes, os próprios gerentes 
do órgão implementador) não vivem o dia a dia da implementação e, assim, por desconhecerem as demandas reais da população alvo, não teriam como orientar decisões e ações. É como se políticos e gerentes trabalhassem no atacado e os burocratas de rua no varejo. No entanto, também podem existir outros fatores, entre eles a falta de comprometimento do burocrata de rua com os objetivos da política, em decorrência talvez do desconhecimento ou falta de consciência de como a política foi concebida, o que pode se refletir em uma alienação do burocrata do processo da política. Aliás, o processo de alienação do burocrata de nível de rua em relação a vários aspectos da política é abordado também por Lipsky (2010), além de Tummers (2012) que propõe, inclusive, uma teoria da alienação que procura explicar a relação desses profissionais com a política.

Ao tratar dos possíveis conflitos entre objetivos dos implementadores de linha de frente e os objetivos organizacionais, Lipsky (2010) alega que os profissionais dos níveis operacionais das organizações públicas não necessariamente compartilham dos mesmos objetivos de seus superiores e, que quando isso ocorre, pode-se esperar que não se esforcem para o alcance dos objetivos da organização. $\mathrm{O}$ autor destaca que se pode esperar certo grau de não conformidade dos funcionários de escalões mais baixos se estes perceberem que seus interesses são diferentes daqueles dos que ocupam níveis organizacionais mais altos. Assim, se os incentivos e sanções disponíveis aos níveis superiores não são suficientes para corrigir essa divergência, pode-se provocar falta de motivação para os burocratas de rua desenvolverem bem suas atividades. $O$ desafio da gerência passa a ser como melhorar a satisfação no trabalho, mantendo a produtividade (LIPSKY, 2010).

Desse modo, pode haver um choque entre as decisões e ações do implementador de linha de frente e o que estabelece as regras organizacionais quanto à orientação e ação desses profissionais. O desencontro de interesses que resulta entre a organização, representada pelos gerentes ou gestores, e o burocrata de linha de frente pode ter implicações para o desempenho da política, embora se saiba que os modelos organizacionais de controle hierárquico por si só não sejam suficientes para explicar esse desempenho (MEYERS e VORSANGER, 2010).

\section{O IMPLEMENTADOR E OS PROCESSOS DE ACCOUNTABILITY}

As decisões e ações do implementador de linha de frente implicam accountability. Embora esse processo esteja fortemente relacionado aos três pontos discutidos anteriormente, preferiu-se pautá-lo separadamente para facilitar sua análise como fator que influencie o comportamento do implementador, mesmo que essa influência seja apenas parcial como sustentam Meyers e Vorsanger (2010). Portanto, é natural que se retomem muitos dos conceitos já abordados neste texto, no sentido de demonstrar como se apresenta a necessidade de accountability.

A accountability é compreendida por Burke (1990) como a responsabilidade de alguém responder por suas ações a um superior, a si próprio, aos seus pares e aos usuários que atende. Lipsky (2010) propõe que as pessoas devem ser consideradas accountable quando existe uma alta probabilidade de que elas sejam responsivas. Essa definição aponta para dois aspectos importantes do conceito, segundo o próprio autor. Primeiro, accountability é um relacionamento entre pessoas ou grupos. Segundo, refere-se a padrões de comportamento. Somente se existe um padrão de comportamento, pode previsivelmente existir accountability. Dessa perspectiva, as tentativas de aumentar a accountability através de controles administrativos podem ser vistas como um esforço para aumentar a congruência entre o comportamento do trabalhador e as políticas públicas por meio de sanções e incentivos aplicados pela organização.

Em um estudo com policiais, Oliveira (2012) afirma que os agentes pesquisados não possuem poder formal, mas têm considerável poder discricionário sobre as regras e os procedimentos a serem aplicados, além de responderem quanto à gestão sobre os bens e o poder de sanção que será aplicado e a quem. O autor também acredita que o poder da discrição é necessário e inevitável, conforme já discutido neste estudo, porque as regras formais não conseguem responder a todos os casos concretos, além dos recursos serem quase sempre insuficientes para atender às demandas dos cidadãos. Diante disso, 0 poder discricionário permite que o agente público seja capaz de responder à realidade.

No entanto, a ampla margem de ação desses agentes deixa em aberto a questão do controle de suas ações, a fim de que a accountability seja assegurada. Pode-se observar que, no processo de implementação da política na linha de frente, o problema mais eloquente seja a distância entre o interesse geral da política e a necessidade específica do cidadão. No meio está o implementador, que precisa tomar uma decisão, que é a de cumprir com as diretrizes escritas da política ou interpretá-la 

políticas públicas

à luz da realidade em que se encontra. Qualquer que seja sua decisão, suas ações serão submetidas a julgamento de acordo com os princípios da ação pública instituídos em lei, das necessidades gerenciais de mensuração de desempenho e da accountability pública (OLIVEIRA, 2012).

Quanto à questão gerencial, observa-se uma lacuna na literatura de implementação em relação ao controle como mecanismo de gestão, possivelmente, porque hoje em dia a questão de controle é menos estudada pelas ciências administrativas e mais pela ciência política. O controle como instrumento de gestão pode ser compreendido como a organização, as políticas e os procedimentos utilizados para garantir: 1) que os programas de governo alcancem seus resultados; 2) que os recursos usados para as entregas desses programas sejam consistentes não apenas com os objetivos das políticas, mas também com os objetivos organizacionais; 3) que os programas sejam protegidos de perdas, fraude e má administração; e 4) que informações confiáveis e oportunas sejam obtidas, mantidas, transmitidas e usadas na tomada de decisão (ALLEN, 1996). Uma vez atendidos esses propósitos, se estaria também respondendo à demanda por accountability pública, principalmente, quando se considera o exercício da discricionariedade pelos implementadores, sem que haja instrumentos adequados de gestão.

Percebe-se claramente, que o campo de estudos sobre a implementação de políticas tem investigado o controle político sobre as burocracias de governo - incluindo a burocracia de nível de rua (MEIER e O'TOOLE Jr., 2006; WATERMAN, ROUSE e WRIGHT, 1998; WINTER, 2003) -; o controle da política pelos subordinados (SCHEFF, 1961); o controle interorganizacional (KOMINIS e DUDAU, 2012); o controle hierárquico ou controle do poder (BREHM, GATES e GOMEZ, 2003); o controle social ou controle democrático (HUPE e HILL, 2007) ou mesmo o controle do comportamento, como preconiza a teoria da relação agente-principal (WINTER, 2003). Entretanto, não tem investigado o controle que visa avaliar o alcance das metas do processo de implementação, bem como o alinhamento desse processo com os objetivos da política, uma forma de accountability organizacional.

Para Lipsky (2010), uma fonte que aumenta as preocupações com a accountability burocrática é a percepção da crise fiscal, e, nesse caso, se servidores públicos não podem demonstrar accountability, é mais uma razão para o corte de seus orçamentos. Lipsky, no entanto, acredita que algumas atividades cujos resultados são qualitativos não são passíveis de demonstrar accountability, sem contar que em muitas ações executadas no nível de rua, o processo é mais importante do que o produto. Essa é uma observação de Oliveira (2012) em seu estudo sobre os agentes implementadores das políticas de segurança. Em situações em que a accountability é difícil de ser demonstrada ou em que possam existir desvios de condutas, pode-se adotar as estratégias pontuadas por Tendler (1998). Em seu estudo, a autora exemplifica que o governo chamou a sociedade para fazer o controle social das ações do governo, bem como a proteção dos servidores dedicados e comprometidos da ingerência indevida de colegas que optaram por aderir a práticas de desvio de conduta.

Em um estudo que procurou especificar as características do contexto em que os burocratas de rua desenvolvem suas atividades e mostrar as consequências dessas características para a accountability profissional no serviço público, Hupe e Hill (2007) estabelecem várias proposições, com destaque aqui para aquelas que afirmam que os burocratas de nível de rua necessariamente têm discricionariedade e são forçados a usá-la. Talvez nesse ponto apareça um dos grandes dilemas apontados por Lipsky (2010), pois além dos burocratas terem de exercer a discrição, também são obrigados a se responsabilizar pelos resultados e pela prestação de contas.

Hupe e Hill (2007) argumentam, ainda, que podem ser necessárias múltiplas accountabilities na prática. Para os autores, isso é até desejável, pois assim aumenta a gama de pontos de influência disponíveis aos cidadãos. Observam, no entanto, que um emaranhado de múltiplas accountabilities pode produzir ações contraditórias, sendo necessário aos burocratas de rua constantemente pesar como agir. Ao mesmo tempo, a avaliação de seus atos, principalmente no nível agregado, permanece um assunto de julgamento político (HUPE e HILL, 2007), mais do que administrativo. Analisar essas accountabilities como praticadas no nível de rua é tema relevante para a pesquisa empírica comparativa (HUPE e HILL, 2007).

Pode-se considerar que a accountability é uma exigência nas sociedades democráticas, enquanto o controle é uma necessidade administrativa. Ambos os processos têm avançado devido ao desenvolvimento de sistemas de informações que tornam o acesso às informações mais fácil, tanto para a organização quanto para os cidadãos. Assim, a análise da existência de controles e das práticas de accountability cumprem dois grandes objetivos da política: a gestão de sua implementação e a prestação de contas para seus principais interessados. 


\section{OS IMPLEMENTADORES E SEU COMPORTAMENTO AUTOINTERESSADO}

Além dos aspectos teóricos já analisados, parte da literatura examinada acredita que o comportamento do implementador é fortemente influenciado por seus próprios interesses, ignorando quase por completo que suas decisões e ações podem ser influenciadas por muitos outros fatores como já demonstrados nesta análise. Essa é a preocupação da abordagem agente-principal, que embasa muitas discussões de accountability e que é frequentemente apresentada e empiricamente testada como um modelo top-down (WATERMAN, ROUSE e WRIGHT, 1998).

Para Eisenhardt (1989), a relação de agência ocorre quando uma parte, o principal, delega trabalho para outra parte, o agente, que realiza o trabalho. Os problemas de agência surgem quando as partes cooperantes têm diferentes objetivos e interesses, diferenças distintas em relação ao risco, bem como quando ambos buscam maximizar sua utilidade. Os pressupostos humanos são o interesse próprio, a racionalidade limitada e a aversão ao risco; e os pressupostos organizacionais são os objetivos parciais conflitantes entre os participantes, a eficiência como um critério de efetividade e a assimetria de informações entre o agente e o principal. Para a autora, a assimetria de informação está ligada ao poder do baixo escalão, e esse, talvez, seja um aspecto importante que permite analisar o comportamento do burocrata do nível de rua.

O modelo agente-principal assume explicitamente que tanto principais quanto agentes são maximizadores de utilidade. Como os agentes tendem a ser oportunistas e egoístas, precisam ser monitorados de forma eficaz, pois se isso não ocorrer irão explorar os principais. A base para tal oportunismo seria a assimetria de informação existente entre o principal e o agente, pois se acredita que o agente possua mais informação do que o principal (MILLER e SARDAIS, 2011; WATERMAN, ROUSE e WRIGHT, 1998). No caso da implementação de política pública, essa assimetria de informações pode ser encontrada na relação burocrata de rua/usuário, burocrata de rua/supervisor e burocrata de rua/político, pois nesse momento o profissional de linha de frente (agente) é quem mais conhece a situação apresentada, e não o principal.

No caso de organizações privadas, o principal pode ser os shareholders ou as próprias organizações, como defendem Lan e Heracleous (2010), enquanto o agente pode ser o trabalhador, o gerente, o diretor ou o próprio conselho de administração. Um problema ao se aplicar essa teoria no setor público é que a unidade de análise são os contratos (EISENHARDT, 1989), o que pode complicar a análise com respeito a quem é o principal da relação, por se tratar de questão no âmbito do Estado. Pinto (2008) sugere que, no caso do Estado, a administração pública seria o principal e seus servidores seriam os agentes. No entanto, tratando-se do setor público, pode haver múltiplos principais, conforme defendem Waterman, Rouse e Wright (1998). Estes autores afirmam que, em nível federal, os principais são o presidente, o Congresso e as cortes, além de outros que os estudos ignoram, tais como a indústria regulada, os grupos de interesse, o público, a mídia e outros atores no nível de rua, como os governos estaduais, as assembleias e as cortes estaduais. Os agentes, por sua vez, seriam seus funcionários de nível de rua.

O escopo ou extensão da agência também varia muito entre diferentes sistemas sociais, mesmo por ocupantes de posições análogas. A agência pode ser coletiva ou individual (SEWEL JR., 1992), e pode ser que os agentes burocratas ajam coletivamente, como unidade corporativa. Isso faz diferença, pois agem no interesse do grupo, o que os tornam mais fortes quanto à capacidade de agência, assim como mais difícil o estabelecimento de formas de controlar seu comportamento da maneira preconizada pela teoria agente-principal (SEWEL JR., 1992). As divergências que muitas vezes ocorrem entre sindicatos e governos, podem muito bem ilustrar as relações agente-principal discutidas teoricamente.

Observa-se, ainda, que os modelos agente-principal são usados para estudar problemas de controle em organizações públicas e privadas, enfatizando os elementos coercitivos de supervisão como forma de induzir a obediência dos empregados. O elemento-chave em todo o modelo é que alguns interesses são conflitantes entre o principal que quer incitar certo comportamento do agente e o agente que pode ter incentivos para não desempenhar todo o trabalho que o principal deseja. $O$ principal tenta controlar o comportamento do agente, mas é restringido ao fazer isso, por causa da assimetria de informação (BREHM, GATES e GOMES, 2003; WINTER, 2003).

Assim, o trabalho do principal é antecipar a resposta racional do agente e desenhar um conjunto de incentivos que contemple os interesses desses agentes, para que ajam da melhor forma possível visando atender aos interesses do principal (BREHM, GATES e GOMES, 2003). Na implementação de uma política, pode-se considerar o relacionamento entre principal e agente como uma cadeia que conecta políticos eleitos, burocratas, gerentes e usuários. Em uma nova política, é complicada 
a dependência do principal, o formulador da política, do pessoal de linha de frente, porque a implementação ocorre na interface entre o burocrata e o usuário e, dessa forma, é difícil para o principal predizer ou observar diretamente o comportamento do burocrata, que detém substancial discricionariedade em sua produção (MEYERS, GLASER e DONALD, 1998).

Esse foi o caso da análise empírica feita por Winter (2003, p. 23), que percebeu que a influência dos executivos políticos sobre os burocratas varia de acordo com o grau de assimetria de informação para vários tipos de comportamento. Os políticos controlam os aspectos visíveis do comportamento de entrega dos serviços, mas têm dificuldade de controlar aspectos invisíveis, tais como o estilo de interação com o cidadão e a forma como respondem a condições particulares de cada cidadão ou empresa em particular. Isto é, a influência do principal sobre o agente é limitada, já que aspectos importantes do comportamento do burocrata estão além de seu controle.

Essa abordagem do agente-principal, como se pode observar, coloca dilemas importantes na análise do comportamento do implementador no processo de implementação de política. Como analisar situações que fogem aos pressupostos individuais subjacentes à teoria? Como analisar processos de implementação baseados em pressupostos de confiança, vocação e altruísmo? Se baseado apenas nos pressupostos econômicos, reduzir-se-ia a implementação a um processo de permanente tensão entre burocratas e a organização pública, o que poderia tornar especialmente as políticas de regulação econômica, grande fonte de conflitos. No entanto, ao desconsiderar completamente esses pressupostos, incorrer-se-ia em riscos de falta de controle e de desvio de comportamento, que não são incomuns na administração pública.

\section{O IMPLEMENTADOR E OS DISPOSITIVOS INSTITUCIONAIS: NORMAS, REGRAS, CRENÇAS E VALORES}

Enquanto a abordagem agente-principal explicaria o comportamento do burocrata de rua pelo autointeresse do indivíduo, abordagens institucionais dariam maior peso a fatores externos ao indivíduo. Vários estudos indicam que o comportamento dos burocratas de nível de rua é pautado por fatores no ambiente institucional da política, tais como as regras, os papéis, as sanções, as ideologias e os valores. Maynard-Moody e Musheno (2003), em seus estudos sobre os burocratas de rua, perceberam que esses profissionais tomam decisões baseadas em suas crenças e em seus sistemas de valores, mas, ao mesmo tempo, as políticas, as regras e a fiscalização administrativa também fazem parte do cálculo do que fazer. Os autores afirmam, ainda, baseados nos resultados de seus estudos, que a obediência à lei e a obediência cultural coexistem no trabalho dos burocratas de nível de rua.

O trabalho de Maynard-Moody e Musheno (2003) se concentrou em revelar os padrões de tomada de decisão que emergem quando leis e crenças (assim como comportamentos e identidades) se entrelaçam no cotidiano do trabalho no nível de rua. Os autores observam que, grande parte da pesquisa atual sobre implementação, foca no entendimento de como os implementadores de nível de rua // foca na observação de como os implementadores de nível de rua aplicam leis, regulamentos e procedimentos nas políticas que executam. Maynard-Moody e Musheno $(2000 ; 2003)$ notam, ainda, que quase todos os aspectos do trabalho das organizações públicas são estruturados por regras e procedimentos. No entanto, observaram que essas regras e procedimentos colocam apenas restrições fracas e parâmetros soltos em torno dos julgamentos dos burocratas do nível de rua. Isso leva os autores a afirmar que ironicamente o trabalho do nível de rua é saturado de regras, mas não é limitado por essas regras, numa referência à autonomia que têm os profissionais sobre suas decisões e ações na implementação das políticas.

No entanto, não se pode esquecer que, mesmo que as regras e procedimentos não estruturem completamente o trabalho dos burocratas (e isso é dado como certo pela literatura revisada, quando se discutiu a discricionariedade), as estruturas organizacionais podem induzir seus integrantes a atitudes e sentimentos próprios (no caso específico, os implementadores), como forma de criar valores cognitivos que são difundidos por meio de processos institucionais (MERTON, 1966; THOENIG, 2010). Percebe-se, ainda, que a "realidade organizacional está teoricamente concebida como uma construção simbólica" (THOENIG, 2010, p. 173).

Com base nessa perspectiva, o que seriam as crenças e os sistemas de valores que pautam as decisões e ações dos burocratas de nível de rua como demonstraram Maynard-Moody e Musheno (2000; 2003), senão o resultado da interação do conjunto 
de fatores institucionais? O conjunto de crenças e valores dos implementadores seria completamente diferente daqueles presentes nas organizações e instituições às quais pertencem? Seria arriscado fazer esse tipo de afirmação, pois isso representaria a negação das evidências de anos de estudos realizados dentro da perspectiva institucional.

Hill e Hupe (2002) apontam que os sociólogos organizacionais exploram as questões sobre a conformidade a regras pelas pessoas dentro das organizações, e que essas questões estão relacionadas aos burocratas de nível de rua porque o processo de formação da política e da implementação ocorre em um contexto organizado onde existem normas, valores, relacionamentos, estrutura de poder e procedimentos padrões de operações que impactam os resultados da implementação. De fato, Merton (1966) já afirmara que as atividades dos "técnicos estão regidas por normas gerais abstratas e claramente definidas" (Ibid., p. 96), e que os "dispositivos institucionais são necessários, a fim de canalizar comportamentos oportunistas e garantir certa estabilidade coletiva" (THOENIG, 2010).

O fato é que analisar o comportamento dos burocratas no processo de implementação sem considerar os aspectos das instituições em que se desenvolve a política e a sua implementação seria ignorar os resultados de muitos estudos que mostram existirem relações importantes das variáveis institucionais com o comportamento do implementador, a começar pela lei e os regulamentos das políticas. Seria também ignorar princípios como o da legalidade, que exige coerência entre a decisão e ação do burocrata e a legislação da política, assim como ignorar os sistemas de crenças e valores das instituições.

\section{PROPOSTA DE RELACIONAMENTO DOS FATORES INFLUENCIADORES DA BUROCRACIA DE NÍVEL DE RUA}

Foi evidenciada pela análise realizada que a pesquisa acadêmica ainda não desenvolveu uma concepção integrada dos fatores que potencialmente influenciam os implementadores, nem apresenta os relacionamentos lógicos e influências mútuas desses elementos. No entanto, é possível inferir que esses relacionamentos existam. A figura 1 permite visualizar como os fatores discutidos ao longo deste artigo moldam o comportamento do implementador da linha de frente no processo de implementação. 
Figura 1

Fatores influenciadores do comportamento do implementador de nível de rua

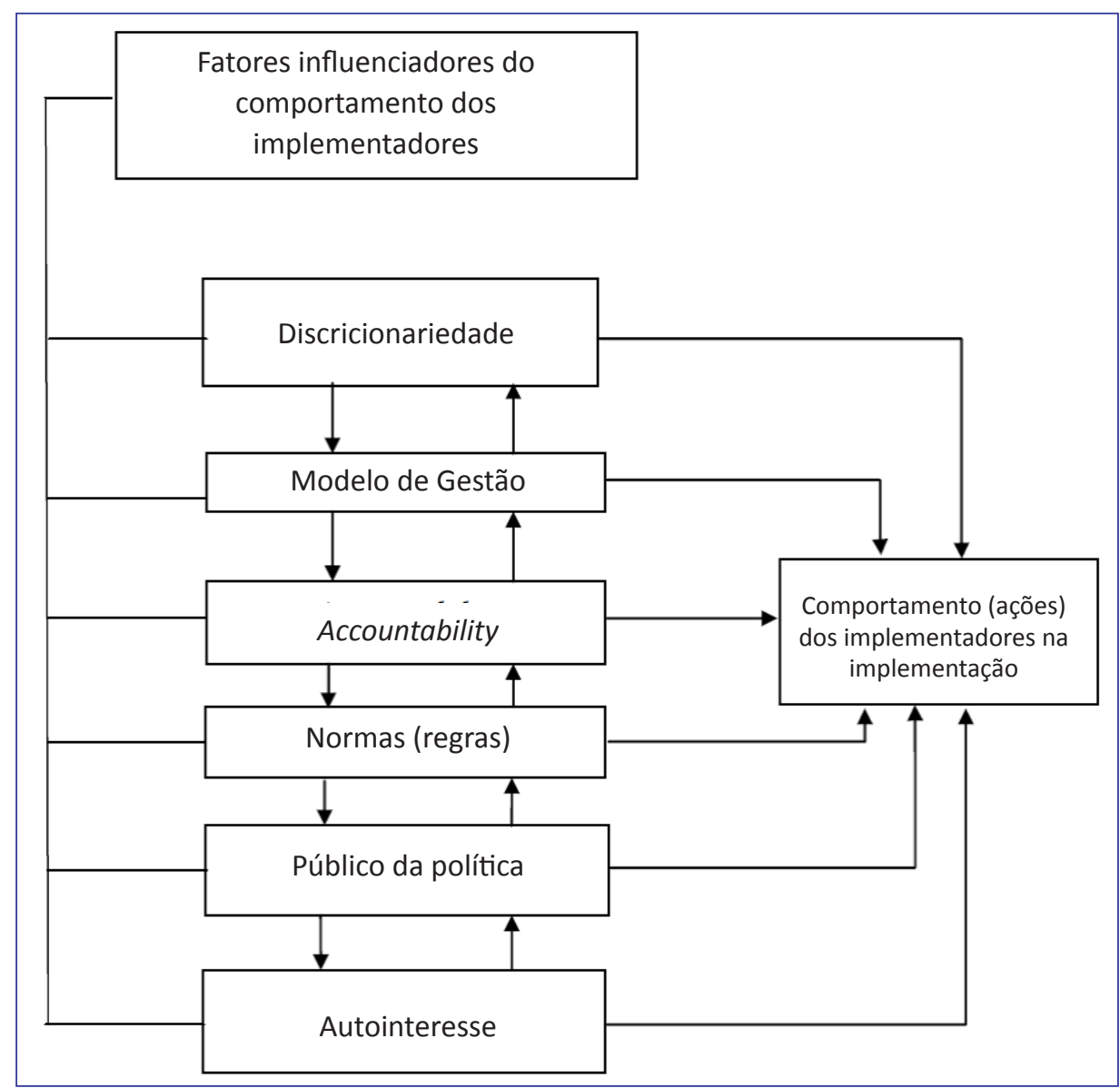

Fonte: elaborado pelos autores (2015).

Como já comentado, a questão do que influencia o comportamento do burocrata de nível de rua vem sendo abordada de forma fragmentada, privilegiando uma ou outra abordagem teórica e um ou outro foco de análise, conforme o interesse do pesquisador. Argumenta-se aqui a importância de refletir sobre como todos esses elementos se relacionam e como combinam e interagem para moldar o comportamento dos implementadores e, consequentemente, o processo e os resultados de implementação. A figura 1 deixa claro que um ou outro fator, por si só, é insuficiente para explicar o fenômeno da atuação do burocrata de nível de rua.

\section{CONSIDERAÇÕES FINAIS}

Este artigo procurou sistematizar o conhecimento sobre o que influencia as decisões e ações do implementador de linha de frente, apresentando um modelo conceitual das tensões e relações existentes. Cabe ainda apontar algumas lacunas no estado atual de conhecimento e direções para futuras pesquisas.

Observou-se que existem muitos fatores que podem influenciar o comportamento do burocrata de rua, com destaque para os fatores relacionais do implementador com os usuários, gerentes e políticos; fatores pessoais, tais como as crenças, valores e autointeresse, assim como fatores gerenciais, que envolvem recursos, sistemas de controle, accountability, padrões de desempenho, entre outros, além de fatores institucionais. 
Observou-se, também, uma variedade de abordagens e teorias pertinentes para a análise e explicação do que determina o comportamento do implementador de linha de frente, e que podem contribuir com a pesquisa sobre o tema pelas múltiplas possibilidades que oferecem para compreensão e explicação do fenômeno de interesse. Essas vantagens, no entanto, parecem ser parciais pela fragmentação teórica do campo, que parece refletir a própria natureza complexa do objeto de pesquisa. Foi verificada a carência de um modelo conceitual que aborde o comportamento do burocrata de nível de rua de forma mais integradora, como aquele abordado neste estudo. Alguns autores defendem esse tipo de abordagem integradora entre os estudos de implementação e as teorias organizacionais e burocráticas, embora se reconheça as dificuldades enfrentadas nas tentativas desse tipo de abordagem, por sua complexidade do ponto de vista metodológico.

Outra lacuna evidenciada se refere ao fato de que, embora a teoria procura entender o comportamento de pessoas no processo de implementação, praticamente, inexistem na literatura sobre burocratas de nível de rua abordagens comportamentais oriundas do campo de conhecimento da psicologia, o que se constitui em oportunidade de pesquisa para a área. É possível apontar também a inexistência de estudos que investiguem quais as áreas ou tarefas onde (levando em consideração as características do trabalho e/ou as características profissionais dos implementadores) seria conveniente ampliar ou diminuir a discricionariedade do profissional da linha de frente.

A teoria também ignora a questão da omissão na aplicação da discricionariedade. Uma possibilidade é que o profissional que omite exercer sua discrição poderia ser visto como o funcionário cumpridor de normas, mas despreocupado com a política. Contudo, há necessidade de pesquisa para explicar tal comportamento.

A conclusão, portanto, é pela necessidade de se aprofundar o conhecimento sobre os determinantes do comportamento do burocrata de nível de rua, uma vez que se tenha em vista melhorar o desempenho das políticas públicas. 


\section{REFERÊNCIAS}

ALLEN, R. I. G. Management control in modern government administration: an introduction. In: OCDE. Management control in modern government administration: some comparative practices. Sigma Papers, n. 4. OCDE Publishing, 1996. Disponível em: <http://www. oecd-ilibrary.org/governance/management-control-in-modern-government-administration_5kml6gb4gn32-en>. Acesso em: 23 out. 2013.

ANTEZANA, N. L. A ambiguidade no processo de implementação de políticas públicas, 2013. Disponível em: <http://repositorio.unb.br/ handle/10482/13785>. Acesso em: 10 out. 2013.

BARTELS, K. P. R. Public encounters: the history and future of faceto-face contact between public professionals and citizens. Public Administration, v. 91, n. 2, p. 469-483, jun. 2013.

BREHM, J.; GATES, S.; GOMEZ, B. Donut shops, speed traps and paperwork: supervision and the allocation of time to bureaucratic tasks. In: KRAUSE, G. A.; MEIER, K. J. Politics, policy, and organization: frontiers in the scientific study of bureaucracy. University Michigan Press, 2003. 348 p. Disponível em: <http://www.untag-smd. ac.id/files/Perpustakaan_Digital_1/BUREAUCRACY\%20Politics,\%20 Policy,\%20and\%20Organizations..\%20Study\%20of\%20Bureaucracy. pdf>. Acesso em: 23 out. 2013.

BRODKIN, E. Z. Reflections on street-level bureaucracy: past, present, and future. Public Administration Review, v. 72, n. 6, p. $940-$ 949, nov./dez. 2012.

BURKE, J. P. Policy implementation and the responsible exercise of discretion. In: PALUMBO, D. J.; CALISTA, D. J. Implementation and the policy process: opening up the black box. Westport, Connecticut: Greenwood Press, 1990. 262 p.

EISENHARDT, K. M. Agency theory: an assessment and review. Academy of management Review, v. 14, n. 1, p. 57-74, 1989.

FERMAN, B. When failure is success: implementation and Madisonian government. In: PALUMBO, D. J.; CALÍSTA, D. J. Implementation and the policy process: opening up the black box. Westport, Connecticut: Greenwood Press, 1990. 262 p.

HILL, M.; HUPE, P. Implementation public policy. London: Sage Publications Ltd., 2002. 226 p.

HUPE, P.; HILL, M. Street-level bureaucracy and public accountability. Public Administration, v. 85, n. 2, p. 279-299, 2007.

JOHN, P. Analysing public policy. 2. ed. London: Pinter, 2012. 213 p. (ed. Kindle).

KEISER, L. R. Understanding street-level bureaucrats' decision making: determining eligibility in the social security disability program. Public management review, v. 70, n. 2, p. 247-57, mar./abr. 2010.

KOMINIS, G.; DUDAU, A. I. Time for interactive control systems in the public sector? The case of every child matters policy change in England. Management Accounting Research, v. 23, n. 2, p. 142 155, jun. 2012.

LAN, L. L.; HERACLEOUS, L. Rethinking agency theory: the view from law. Academy of Management Review, v. 35, n. 2, p. 294-314, 2010.
LESTER, J. P. et al. Public policy implementation: evolution of the field and agenda for future research. Policy Studies Review, v. 7, n. 1, p. 200-216, 1987.

LESTER, J. P.; GOGGIN, M. L. Back to the future: the rediscovery of implementation studies. Policy current. Newsletter of the Public Policy Section American Political Science Association, v. 8, n. 3, p. 1-12, set. 1998.

LIMA, M. L. O. F.; MEDEIROS, J. J. Empreendedores de políticas públicas na implementação de programas governamentais. Rev. Adm. Pública, v. 46, n. 5, p. 1251-270, set./out. 2012.

LINDER, S. H.; PETERS, G. A Design perspective on policy implementation: the fallacies of misplaced prescription. Review of Policy Research, v. 6, n. 3, p. 479-475, 1987.

LIPSKY, M. Street-level bureaucracy. Dilemmas of the individual in public service. $30^{\text {th }}$ anniversary expanded edition. New York: Russell Sage Foundation, 2010. 275 p.

LOTTA, G. S.; PAVEZ, T. R. Agentes de implementação: mediação, dinâmicas e estruturas relacionais. Cadernos de Gestão Pública e Cidadania, v. 15, n. 26, p. 109-125, 2010.

MAJONE, G.; WILDAVSKY, A. Implementation as evolution. In: PRESSMAN, J. L.; WILDAVSKY, A. Implementation, 3. ed. Berkeley: University of California Press, 1984. 281 p.

MATLAND, R. E. Synthesizing the implementation literature: the ambiguity-conflict model of policy implementation. Journal of Public Administration Research and Theory, v. 5, n. 2, p. 145-174, 1995.

MAY, P. J.; WINTER, S. C. Politicians, managers, and street-level bureaucrats: influences on policy implementation. Journal of Public Administration Research and Theory, v. 19, n. 3, p. 453-76, 2007.

MAYNARD-MOODY, S.; MUSHENO, M. State agent or citizen agent: two narratives of discretion. Journal of Public Administration Research and Theory. v. 10, n. 2, p. 329-358, 2000.

MAYNARD-MOODY, S.; MUSHENO, M. Cops, teachers, counselors: stories from the front lines of public services. Ann Arbor: University of Michigan Press, 2003. 221 p.

MAYNARD-MOODY, S.; MUSHENO, M. Social equities and inequities in practice: street-level workers as agents and pragmatists. Public Administration Review, Special Issue, v. 72, n, 51, p. S16-S23, nov./ dez. 2012.

MEIER, K. J.; O'TOOLE Jr., L. J. Political control versus bureaucratic values: reframing the debate. Public Administration Review, v. 66, n. 2, p. 177-192, mar. 2006.

MELLO, C. A. B. Curso de direito administrativo. 27. ed. São Paulo: Malheiros Editores, 2010. 1119 p.

MERTON, R. K. Estrutura burocrática e personalidade. In: Sociologia da burocracia. Tradução: CAMPOS, E. Rio de Janeiro: Zahar Editores, 1966. $135 \mathrm{p}$. 
MEYERS, M. K.; GLASER, B.; DONALD, K. M. On the front line of welfare delivery: area workers implementing policy reforms. Journal of Policy Analysis and Management, v. 17, n. 1, p. 1-22, 1998.

MEYERS, M. K; VORSANGER, S. Burocratas de nível de rua e a implementação de políticas públicas. In: PETER, B. G. PIERRE, J. Administração Pública: coletânea. Brasília: ENAP: 2010. 649 p.

MILLER, D.; SARDAIS, C. Angel agents: agency theory reconsidered. Academy of Management Perspective, v. 25, n. 2, p. 6-13, maio 2011.

OLIVEIRA, A. Burocratas da linha de frente: executores e fazedores das políticas públicas. Rev. Adm. Pública, v. 46, n. 6, p. 1551-74, nov./dez. 2012.

O'TOOLE Jr., L. J. Research on policy implementation: assessment and prospects. Journal of Public Administration Research and Theory, v. 10, n. 2, p. $263-88,2000$.

PALUMBO, D. J.; MAYNARD-MOODY, S.; WRIGHT, P. Measuring degrees of successful implementation: achieving policy versus statutory goals. Evaluation Review, v. 8, n. 1, p. 45-74, fev. 1984.

PINTO, R. E. As reformas do Estado e o paradigma da Nova Economia Institucional. In: PEIXOTO, J. P. M (Org.). Governando o governo: modernização da administração pública no Brasil. São Paulo: Atlas, 2008. $139 \mathrm{p}$.

PIRES, R. R. C. Burocracia, discricionariedade e democracia: alternativas para o dilema entre controle do poder administrativo e capacidade de implementação. Cadernos Gestão Pública e Cidadania, v. 14 , n. 54 , p. 147-187, jan./jun. 2009a.

PIRES, R. R. C. Estilos de implementação e resultados de políticas públicas: fiscais do trabalho e o cumprimento da lei trabalhista no Brasil. DADOS, Revista de Ciências Sociais, v. 52, n. 3, p. 735-769, 2009b.

PRESSMAN, J. L.; WILDAVSKY, A. Implementation, 3. ed. Berkeley: University of California Press, 1984. 281 p.

SABATIER, P. A.; MAZMANIAN, D. The implementation of public policy: a framework of analysis. Policy Studies Journal, v. 8, n. 4, p. 538-60, jan. 1980.

SCHARPF, F. W. Games real actors play: actor-centered institutionalism in policy research. Colorado, USA: Westview Press, 1997. 318 p.

SCHEFF, T. J. Control over policy by attendants in a mental hospital. Journal of Health and Human Behavior, v. 2, n. 2, p. 93-105, Summer 1961.
SEWEL Jr., W. H. A Theory of structure: duality, agency, and transformation. The American Journal of Sociology, v. 98, n. 1, p. 1-29, jul.1992.

TENDLER, J. Bom governo nos trópicos: uma visão crítica. Rio de janeiro: Revan; Brasília, DF: ENAP, 1998. 286 p.

THOENIG, J. C. Teorias institucionais e instituições públicas: tradições e conveniências. In: PETER, B. G. PIERRE, J. Administração Pública: coletânea. Brasília: ENAP: 2010. 649 p.

TUMMERS, L. Policy alienation and the power professionals. Cheltenhan: Edward Elgar Publishing, 2013. 188 p.

TUMMERS, L.; STEIJN, B.; BEKKERS, V. Explaining the willingness of public professionals to implement public policies: content, context, and personality characteristics. Public Administration, v. 90, n. 3, p. 716-36, 2012.

VAN METER, D. S.; VAN HORN, C. E. The policy implementation process: a conceptual framework. Administration \& Society, v. 6, n. 4, p. 445-88, fev. 1975.

WATERMAN, R. W.; ROUSE, A.; WRIGHT, R. The venues of influence: a new theory of political control of the bureaucracy. Journal of Public Administration Research and Theory, v. 8, n. 1, p. 13-38, 1998.

WEBER, M. Os fundamentos da organização burocrática: uma construção do tipo ideal. In: Sociologia da burocracia. Tradução: CAMPOS, E. Rio de Janeiro: Zahar Editores, 1966. 135 p.

WILSON, J. Q. Bureaucracy: what government agencies do and why they do it. New York, United States of America: Basic Books, 2000. 433 p.

WINTER, S. C. Political control, street-level bureaucrats and information asymmetry in regulatory and social policies. Paper prepared for the Annual Research Meeting of the Association for Public Policy Analysis and Management held in Washington D. C, November, 2003. 1-35 p. Disponível em: <http://www.sfi-campbell.dk/graphics/sfi/forskerfiler/soren_winter/appam03a.prn.pdf >. Acesso em: 23 out. 2013.

WINTER, S. C. Perspectivas de implementação: status e reconsideração. In: PETER, B. G. PIERRE, J. Administração Pública: coletânea. Brasília: ENAP: 2010. 649 p.

Vicente da Rocha Soares Ferreira

Doutor em administração pela Universidade de Brasília (UnB); Professor assistente da Faculdade de Administração, Ciências Contábeis e Economia (FACE/UFG).Email: vicenterocha@ufg.br

Janann Joslin Medeiros

Doutora em Administração Pública pela University of Southern Califórnia; Pesquisadora Associada do PPGA/UnB. E-mail: janann@unb.br 